\title{
PRONIOSOMAL GEL OF FLURBIPROFEN: FORMULATION AND EVALUATION
}

\author{
Prajapati $\mathrm{SK}^{1}$, * Kumar $\mathrm{S}^{1}$, Sahu VK ${ }^{2}$, Prakash $\mathrm{G}^{2}$ \\ Institute of Pharmacy, Bundelkhand University, Jhansi-284128, INDIA ${ }^{1}$ \\ KNIMT, Faculty of Pharmacy, Sultanpur, INDIA ${ }^{2}$ \\ Corresponding Author's Email: Sunil.sunilpharma.kumar@gmail.com
}

Received 20 Oct 2011; Revised 23 and 25 Nov 2011; Accepted 25 Nov 2011, Available online 20 Jan 2012

\begin{abstract}
The purpose of this research is to design proniosomal gel drug delivery system of flurbiprofen in a trial to overcome the adverse effects associated with oral administration of the drug. This can be overcome by the use of vesicular drug delivery system. Encapsulation of a drug in vesicular structure can be predicted to prolong the existence of the drug in the systemic circulation and thus enhance penetration into target tissue and reduce toxicity. Due to the limited solvent system present, the proniosomes formed were the mixture of many phases of liquid crystal, viz. lamellar, hexagonal and cubic phase liquid crystals. The potential of proniosomes as a transdermal drug delivery system of flurbiprofen was investigated by encapsulating the drug in various formulations of proniosomal gel composed of various ratios of sorbitan fatty acid esters, cholesterol, prepared by coacervation-phase separation method. The formulated systems were characterized in vitro for size, vesicle count, drug entrapment, drug release profiles and vesicular stability at different storage conditions. Stability studies for proniosomal gel were carried out for 4 weeks. The method of proniosome loading resulted in an encapsulation yield of $30.6-75.4 \%$. Invitro studies showed prolonged release of entrapped flurbiprofen. At refrigerated conditions, higher drug retention was observed. It is evident from this study that proniosomes are a promising prolonged delivery system for flurbiprofen and have reasonably good stability characteristics.
\end{abstract}

Keywords: Proniosomes, flurbiprofen, In-vitro release, Transdermal delivery, Stability studies.

\section{INTRODUCTION}

Non-ionic surfactant vesicles known as niosomes are microscopic lamellar structures formed on admixture of a non-ionic surfactant, cholesterol and dicetyl phosphate with subsequent hydration in aqueous media. Proniosomes offer a versatile vesicle drug delivery concept with potential for delivery of drugs via transdermal route. This would be possible because proniosomes form niosomes upon hydration with water from skin following topical application under occlusive conditions. Proniosomes minimizes problems of niosomes physical stability such as aggregation, fusion and leaking and provide additional convenience in transportation, storage and dosing. Transdermal therapeutic system has generated an interest as this system provides the considerable advantage of a non-invasive parenteral route for drug therapy, avoidance of first pass gut and hepatic metabolism, decreased side effects and relative ease of drug. Provesicular systems had attracted researchers as an alternate strategy for transdermal delivery of drugs because of the non-toxicity and penetration effect of lecithin/surfactants. Provesicular systems have been exploited in oral drug delivery in the form of tablets, beads or capsules and have shown improved dissolution and absorption characteristics.

Based on the investigations provesicular systems appear to be an alternate drug carrier for various routes of drug administration. Flurbiprofen, are nonsteroidal antiinflammatory drug (NSAIDs) is used for the relief of pain and inflammation associated with rheumatoid arthritis and osteoarthritis. ${ }^{1}$ It exhibits anti-inflammatory, analgesic and antipyretic activities. It is also used in mild to moderated pain including dysmenorrheal and migraine. Flurbiprofen is more potent than Ibuprofen but has more gastric side effect like peptic ulceration and severe gastrointestinal bleeding may occurs. The plasma half life $\left(t_{1 / 2}\right)$ of flurbiprofen is $4-6$ hours. Hence repeated administration of high dose $(100 \mathrm{mg}$ : three time a day) is required for effective management of rheumatoid arthritis and osteoarthritis. It will be also affected through transdermal route because of its size, nature and chemistry, these systems give better drug permeability from biological bioavailability membranes and helps in solubilization of some practically insoluble drugs and hence solve problems of many drug. ${ }^{2}$ To overcome the problem like gastric side effect, short half life and low bioavailability etc of flurbiprofen can be solved by developing the formulation of flurbiprofen as proniosome gel.

\section{MATERIALS:}

Flurbiprofen was a gift from F.D.C. Mumbai, cholesterol, and dialysis tubing was purchased from Hi-Media Laboratories (Mumbai, India). Span 20, 40, 60, 80 and BRIJ 35 were purchased from Central Drug House (Delhi, India). All other chemicals and solvents were of analytical grade and obtained from Central Drug House Delhi, India. 
Kumar et al

METHOD:

Proniosomal gel was prepared by a coacervation-phase separation method. Precisely weighed amounts of surfactant, cholesterol and drug were taken in a clean and dry wide mouthed glass vial of $5.0 \mathrm{ml}$ capacity and alcohol $(0.5 \mathrm{ml})$ was added to it. All the ingredients were mixed well with a glass rod; the open end of the glass bottle was covered with a lid to prevent the loss of solvent from it and warmed over water bath at $60-70^{\circ} \mathrm{C}$ for about 5 min until the surfactant mixture was dissolved completely. Then the aqueous phase $(0.1 \%$ glycerol solution) was added and warmed on a water bath till a clear solution was formed which was converted into proniosomal gel on cooling. The gel so obtained was preserved in the same glass bottle in dark conditions for characterization. Compositions of proniosomal gel formulations are given in Table1.

\section{CHARACTERIZATION OF PRONIOSOMAL GEL:}

\section{Optical microscopic examination:}

Hydration of proniosomal gel (100mg) was done by adding saline solution $(0.9 \%$ solution) in a small glass vial with occasional shaking for $10 \mathrm{~min}$. The dispersion was observed under optical microscope at $100 \mathrm{x}$ magnification. The sizes of 200-300 vesicles were measured using a calibrated ocular and stage micrometer (Erma, Tokyo) fitted in the optical microscope. ${ }^{4}$

\section{Entrapment efficiency}

To evaluate the loading capacity of proniosomal systems for flurbiprofen, proniosomal gel $(100 \mathrm{mg})$ was dispersed in distilled water and warmed a little for the formation of niosomes. Then the dispersion was centrifuged at $18000 \mathrm{rpm}$ for $40 \mathrm{~min}$ at $5^{\circ} \mathrm{C}$ (Remi CPR-24 centrifuge). The clear fraction was used for the determination of free drug at 247.0 $\mathrm{nm}$ spectrophotometrically. The percentage encapsulation efficiency was calculated from Equation $1 . .$.

$\%$ Encapsulation Efficiency $=[1-$ (Unencapsulated drug / Total drug)] x $100^{7,9}$

\section{In-Vitro Release}

The in vitro drug release studies of proniosomal gel were carried out by means of treated cellophane membrane. Invitro release studies on proniosomal gel were performed using locally Fabricated Franz-diffusion cell. The capacity of receptor compartment was $15 \mathrm{ml}$. The area of donor compartment exposed to receptor compartment was $1.389 \mathrm{~cm}^{2}$. The dialysis cellophane membrane (MMCO14KDC) was mounted between the donor and
\& Therapeutics; 2012, 2(1)

receptor compartment. A weighed amount of proniosomal gel was placed on one side of the membrane.

The receptor medium was saline phosphate buffer $\mathrm{pH}$ 7.4. The receptor compartment was surrounded by a water jacket to maintain the temperature at $37 \pm 1^{\circ} \mathrm{C}$. Heat was provided using a thermostatic hot plate with a magnetic stirrer. ${ }^{71}{ }^{14}$ The receptor fluid was stirred by a Teflon-coated magnetic bead fitted to a magnetic stirrer (Bio-Craft Scientific Systems Pvt. Ltd., Agra). At each sampling interval, $(1 \mathrm{ml})$ were withdrawn and were replaced by equal volumes of fresh receptor fluid on each occasion. Samples withdrawn were analyzed spectrophotometrically (Shimadzu-1700) at 247 nm. ${ }^{15}$

\section{Stability Studies:}

The ability of vesicles to retain the drug (Drug Retention Behaviour) was assessed by keeping the proniosomal gel at three different temperature conditions, i.e., Refrigeration Temperature $\left(4-8^{0} \mathrm{C}\right)$, Room Temperature $\left(25 \pm 2^{0} \mathrm{C}\right)$ and oven $\left(45 \pm 2^{0} \mathrm{C}\right)$. Throughout the study, proniosomal formulations were stored in aluminum foil-sealed glass vials.

\section{RESULTS AND DISCUSSION}

Proniosome gel containing flurbiprofen were prepared by Coacervation phase separation method. Formation of vesicle mainly depends on the concentration of cholesterol and surfactant ratio.Table1 show that the entrapment efficiency of different optimized formulation. The entrapment efficiency of flurbiprofen within the formulation from $40.6 \%$ for span 80 vesicle (SKJ4) to high as $82.56 \%$ for Brij 35 (SKK3) vesicle show higher entrapment efficiency for Brij 35 formulation can be attributed to its length of longer side chain, and it easily diffuse into receptor membrane integrity, orientation and packaging ability.

The entrapment efficiency of proniosomal gel was attributed due to the amphiphillic nature of the drug. The entrapment efficiency was found maximum for SKK3 formulation due to higher HLB value, of the formulation, which result in larger vesicle hence more entrapment of drug into the vesicle. The effect of cholesterol on flurbiprofen entrapment was varied according to the nonionic surfactant used, cholesterol was found to have little effect on the flurbiprofen entrapment. The results of analysis reports are shown in the (Table 2); it shows that vesicle size decrease with decrease in HLB value. Vesicle size decreases in the following manner span $20>$ span $40>$ span $60>$ span $80>$ Brij 35> span 80, i.e. higher the HLB value result in reduction in surface free energy which allow to form vesicle of larger and hence small area exposed to dissolution medium.

Table 1: Composition of proniosomal gel formulation

\begin{tabular}{|l|l|l|l|l|l|l|l|l|}
\hline F. Code & Drug $(\mathbf{m g})$ & Span20 $(\mathbf{m g})$ & Span40 $(\mathbf{m g})$ & Span60 (mg) & Span80 $(\mathbf{m g})$ & Brij35 $(\mathbf{m g})$ & CHL & Solvent ratio $(\mathbf{m l})$ \\
\hline SKG3 & 50 & 50 & - & - & - & - & 50 & 0.5 \\
\hline SKH3 & 50 & - & 50 & - & - & - & 50 & 0.5 \\
\hline SKI3 & 50 & - & - & 50 & - & - & 50 & 0.5 \\
\hline SKJ3 & 50 & - & - & - & 50 & - & 50 & 0.5 \\
\hline SKK3 & 50 & - & - & - & - & 50 & 50 & 0.5 \\
\hline
\end{tabular}


Table: 2 various result of proniosomal gel formulation

\begin{tabular}{|c|c|c|c|c|}
\hline $\begin{array}{c}\text { S. } \\
\text { No. }\end{array}$ & $\begin{array}{c}\text { F. } \\
\text { Code }\end{array}$ & $\begin{array}{c}\text { Vesicle size } \\
\text { (nm) }\end{array}$ & $\begin{array}{c}\text { \% Drug } \\
\text { Entrapment }\end{array}$ & $\begin{array}{c}\text { \% drug } \\
\text { released }\end{array}$ \\
\hline 1. & SKG3 & 375.2 & $57.3 \pm 1.97$ & $57.78 \pm 0.45$ \\
\hline 2. & SKH3 & 330.6 & $62.6 \pm 1.65$ & $62.75 \pm 0.87$ \\
\hline 3. & SKI3 & 305.6 & $76.0 \pm 1.98$ & $68.12 \pm 0.86$ \\
\hline 4. & SKJ3 & 265.4 & $57.3 \pm 1.63$ & $74.85 \pm 0.56$ \\
\hline 5. & SKK3 & 315.6 & $82.56 \pm 1.55$ & $80.42 \pm 0.67$ \\
\hline
\end{tabular}

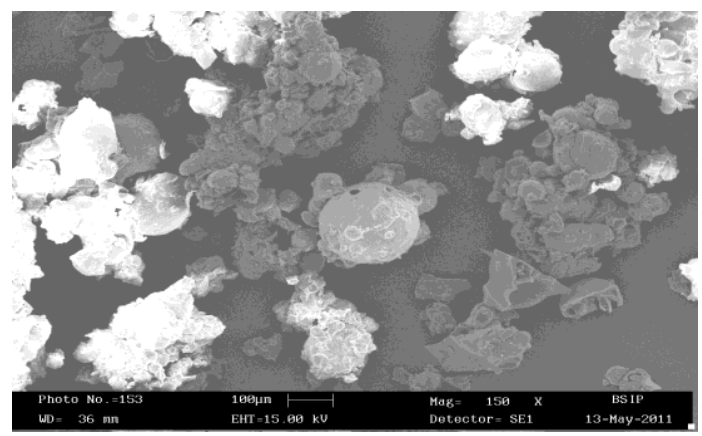

The proniosomal formulation having low cholesterol content was found to cause low entrapment efficiency, which might be because of leakage of vesicle. The higher entrapment may be explained by high cholesterol content $(50 \%$ of the total lipid) reported that entrapment efficiency increase with increasing cholesterol content. It was also observed that very high cholesterol content had a lowering effect on drug entrapment to the vesicle. This could be due to the fact that cholesterol beyond a certain level starts disrupting the regular bilayer structure leading to loss of drug entrapment. ${ }^{15}$

This result are also observed and similar as study in the proniosomal formulation using Brij 35, span 60 and tween 80 surfactant. In this prepare vesicle using Brij 35: cholesterol show better drug release in Comparision to other surfactant. ${ }^{15}$ Our finding results are observed similar as study in Brij 35, Brij 58, and Brij 92 Brij 52 etc. The conclusion of this study show that Brij 35 did not form niosome in the absence of cholesterol, but in the presence of cholesterol niosome formed and vesicle shows more stable and less leaky. ${ }^{16}$

This result are also observed in a comparative study on the effect of some polyoxyethylene alkyl ether like (Brij 78, Brij 92 , Brij 72, Brij 52) and sorbitan fatty acid ester surfactants on the performance of transdermal proniosomal gel using experimental design. In this the Brij 52 show similar property as compare to Brij 35.The findings of this study shows that the niosome formulation prepared with Brij 52 was better drug release in Comparision to other Brij Component.

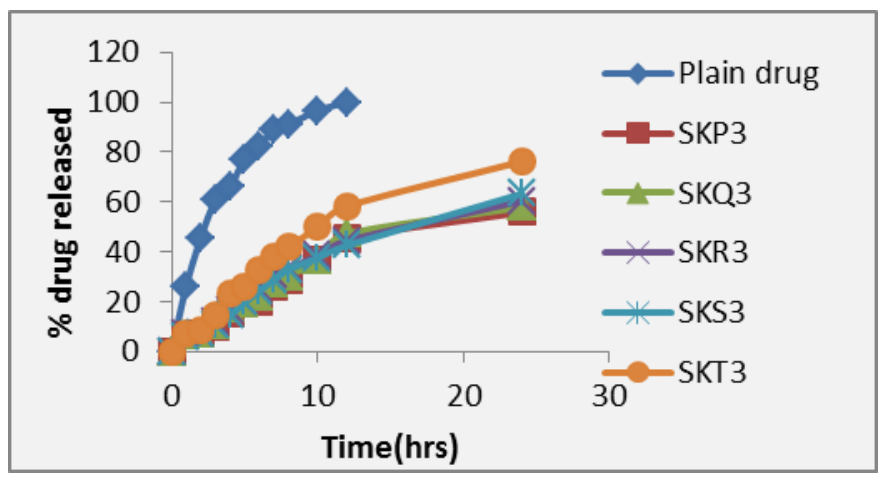

Figure: 1 In-vitro drug release profile of selected proniosomal gel formulation

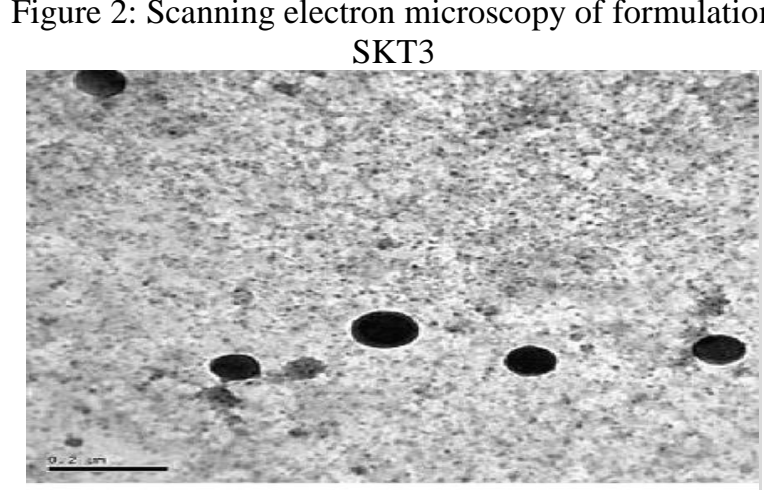

Figure 3: Transmission electron photomicrograph of SKT3

Most of the surfactant used to make non-ionic surfactant vesicle have low aqueous solubility, however freely soluble non-ionic surfactant such as Brij 35 can form micelles on hydration due to the presence of more polar head group in the chain, in the addition of cholesterol they abolish the more polar part present in surfactant mainly due to lipophillic in nature and help in formation of vesicle in the eqiumolar ratio of Brij 35 and cholesterol show better result (1:1). The proniosome formation takes place from Brij 35 with the presence of cholesterol, the length of alkyl chain show a crucial factor of permeability, Brij 35 have long lauryl $\left(\mathrm{c}_{12}\right)$ chain, thus the long chain influence the HLB of the surfactant and also lead to the higher drug entrapment efficiency and also show better stability of the proniosome using Brij 35. Cholesterol is one of the most important additives included in the formulation in order to prepare stable niosome. Cholesterol stabilizes bilayer, prevents leakiness and retards permeation of solutes enclosed in the aqueous core of these vesicle which could be able to effectively prevent leakage of drug from niosome. Cholesterol is thus included in 1: 1 molar ratio (non-ionic surfactant: cholesterol), show better result in the case of Brij 35 . Thus it can be concluded that Brij 35 show highest drug release by the fact that niosome exhibit an alkyl chain lengthdependent drug release

In-vitro drug release was carried out by locally fabricated Franz diffusion cell. The ability of ethanolic lipid vesicles called ethosomes to deliver flurbiprofen was investigated by determining the flux of flurbiprofen. The data of percent cumulative amount of flurbiprofen permeated per unit area across dialysis membrane via various formulations was given. The amount of drug released from different 
proniosomal gel formulation was found in order of SKK3 > SKJ3 > SKI3 > SKH3 > SKG3. It was found that SKK3 showed a controlled release property from 10-24 hrs. The result of cumulative $\%$ drug release $10^{\text {th }}$ hour was found to be $45.12 \% \& 80.42 \%$ at 24 hour . Thiss mins it show a better controlled property. The release profile was found constant between 10-24 hours. So the formulation was found to exhibit a zero order controlled release profile. Other formulation SKG3, SKH3, SKI3, SKJ3, also show good controlled release property. The in-vitro release of flurbiprofen proniosomal gel was limited by two barriers, namely phospholipids bilayer \& dialysis membrane.

The formulation SKK3 (50\% Brij 35 and 50\% cholesterol) showed highest amount of \% drug released $(80.42 \%)$. The enhanced \% drug release obtained from the proniosomal gel system could be justified on the basis of dual function performed by ethanol present in the proniosomal formulations, length of side chain, i.e. fluidizing both the vesicular lipid bilayer and greater malleability to the vesicles and enhancing permeability of the skin.

Overall, the data clearly indicate that the proniosomal gel formulation SKK3 (50\% w/w cholesterol and 50\% w/w Brij$35)$ showed the highest entrapment efficiency (82.56\%), optimum size $(315.6 \mathrm{~nm})$, highest cumulative amount of $\%$ drug released $(80.42 \%)$. Thus justifying itself as an optimized formulation and used for further skin in-vivo studies.

\section{Stability study}

In order to determine the percent drug remaining entrapped in vesicles and percent drug lost from Proniosome gel subjecting at temperature $4 \pm 2^{\circ} \mathrm{C}, 37 \pm 2^{\circ} \mathrm{C}$ and $45 \pm 2^{\circ} \mathrm{C}$ for 45 days, were determined drug lost at time interval of 15 days. On the basis of entrapment efficiency and controlled release property, formulation SKK3 selected for the stability studies. Stability study was carried out in term of \% drug leacked.

Results showed that proniosomal gel formulation was quite stable at refrigeration and room temperature. In this

\section{REFERENCES}

1. Shahiwala A, Misra A. Studies in topical application of niosomally entrapped nimesulide. J Pharm Pharm Sci 2002; 5(3): 220-225.

2. Khandare JN, Madhavi G, Tamhankar BM. Niosomes: Novel drug delivery system. East Pharm 1994; 37:61-64.

3. Fang JY, Yu SY, Wu PC, Huang YB, Tsai YH. In-vitro skin permeation of estradiol from various proniosomes formulation. Int J Pharm 2001; 215: 91-99.

4. Hu C, Rhodes DG. Proniosomes: A Novel Drug Carrier Preparation. Int J Pharm 1999; 185(1): 23-35.

5. Wu PC, Huang YB, Chang JJF, Chang JS, Tsai YH. Evaluation of pharmacokinetics and

6. pharmacodynamics of captopril from transdermal hydrophilic gel in normotensive rabbit and

7. Spontaneously hypertensive rats. Int J Pharm 2000; 209: 8794.

8. Abubkar $\mathrm{O}$ Nur, Zhang JS. Recent progress in sustained/controlled oral delivery of captopril: An overview. Int J Pharm 2000; 194: 139-146.

9. Yoshioka T, Sternberg B, Florence A. T. Preparation and properties of vesicles (Niosomes) of sorbitan monoesters condition not much leakage of drug was found at there temperature. Percent drug retained at $45^{\circ} \mathrm{C}$ might have decreased due to the melting of surfactant and lipid present in the formulation to the proniosomal gel formulation can be stored at refrigeration and room temperature. Thus it can be concluded that the shelf life of proniosomal powder formulation is more than the proniosomal formulation. Because in dry surfactant can be avoided, by forming the suspension as needed, precipitation and aggregation can also be avoided.

\section{CONCLUSION}

Thus from above study it can be concluded that the proniosomes gel posses higher entrapment efficiency and utilizes alcohol, which itself act as penetration enhancer. The elicited an increase of the percutaneous permeation of flurbiprofen in-vitro and. In addition, In-vitro experiments showed that flurbiprofen proniosomes gel can ensure a sustained release of the drug and hence a prolongation of its therapeutic activity, which can be related to an accumulation of flurbiprofen in the skin.

These findings are very encouraging and confirm that proniosomes are a very promising carrier for the topical administration due to the enhanced delivery of drugs through the skin thus prompting various opportunities for the development of suitable therapeutic strategies through the topical route. The formulation is easy to scale up as the procedure is simple and do not involve lengthy procedure and unnecessary use of pharmaceutically unacceptable additives. It offers direct fabrication of transdermal patch and do not require dispersion of vehicle into polymer matrix.

\section{ACKNOWLEDGEMENT}

The authors acknowledge the financial support received from my parents. FDC Pvt Ltd Mumbai, Dr Sunil Kumar Prajapati (Guide) and institute of Pharmacy bundelkhand University Jhansi for their support and encouragement to carry out this work.

(Span- 20, Span- 40, Span- 60 and Span- 80) and a sorbitan triester (Span- 85). Int. J. Pharm. 1994, 105, 1-6

10. Lusia D. Marianecci C. Novel pH sensitive non-ionic surfactant vesicles: comparison between Tween 21 and Tween 20 . colloids and surfaces B: Biointerfaces 2011,82, 18-24

11. Tangri P, Khurana S. Niosomes: Formulation and evaluation. International journal of biopharmaceutics 2011, 2(1), 47-53.

12. Singh J, Robinson DH. Controlled release kinetics of captopril form tableted microcapsules. Drug Dev Ind Pharm 1988; 14(4): 545-560.

13. Leung SHS, Robinson JR. The contribution of anionic polymer structure feature to mucoadhesion. J Contrl Rel 1988; 5: 223231.

14. Sheth PR, Tossounian J. The hydrodynamically balanced system (HBSTM): A novel drug delivery system for oral use. Dev Ind Pharm. 1984; 10(2): 313-339.

15. Abdelbary .G, El-gendy N. Niosome-Encapsulated Gentamicin for Ophthalmic Controlled Delivery. AAPS PharmSciTech, 2008, 105 8-9105. 
16. Pardakhty A, Varshosaz J. In vitro study of polyoxyethylene alkyl ether niosomes for delivery of insulin. International Journal of Pharmaceutics 2007, 318, 130-141.

17. Zhou XH, Li Wan PA. Stability and in-vitro absorption of captopril, enalapril and lisinopril across the ratintestine. Biochem Pharmacol 1994; 47: 1121-1126.

18. Tripathi KD. Essentials of Medical Pharmacology. New Delhi, India, Jaypee Brothers, 2003 pp 449-454.

19. Jain NK, Vora B, Khopade AJ. Proniosome based transdermal delivery of levonorgestrel for effective contraception. J Control Rel 1998; 54: 149-165.

20. Nagarsenker MS, Londhe VY, Nadkarni GD. Preparation and evaluation of liposomal formulation of tropicamide for occular delivery. Int J Pharm 1999; 190: 63-71.

21. Bhatia A, Kumar R, Katare OP. Tamoxifen in topical liposomes: Develoment, characterization and invitro evaluation. J Pharm Pharm Sci 2004; 7(2): 525-259.

22. Joshi YM, Bachman WR, Jani NB. New pharmaceutical composition in the form of beadlets and method. European Patent 1988; EP 288732: A2. 